\title{
Degradation of 4-methylbenzylidene camphor (4-MBC) Using Fenton, UV Light Irradiation and Photo-Fenton
}

\author{
Chunmei Ji, Chen Wang ${ }^{*}$, Jing Sun and Yadong Yu \\ School of Environmental Science and Engineering, Qilu University of Technology \\ Key Laboratory of Cleaner Production and Industrial Waste Recycling and Resourcization in Universities of Shandong \\ Qilu University of Technology, Jinan, Shandong Province, China. \\ Corresponding Email: shanqing123@126.com
}

\begin{abstract}
As one of the most commonly employed UV-filters, 4-methylbenzylidene camphor (4-MBC) has been shown to accumulate in the environment and have endocrine disrupting activity. 4-MBC cannot be degraded completely by common methods in wastewater treatment plants. To prevent the environmental problems caused by 4-MBC from being more serious, finding effective method to degrade 4-MBC is essential. In this research, Fenton reaction and photo-Fenton was employed to degrade the 4-MBC. Orthogonal experimental design was employed to evaluate the influence of factors $\left(\mathrm{Fe}^{2+}, \mathrm{H}_{2} \mathrm{O}_{2}, \mathrm{pH}\right.$ and reaction time) on the degradation of 4-MBC. The degradation rate reached to $66.01 \%$ in Fenton process and $96.71 \%$ in photo-Fenton process. UV light irradiation was also employed to degrade 4-MBC. After being irradiated by mercury lamp (300W) $90 \mathrm{~min}$, the concentration of the $4-\mathrm{MBC}$ reduced $85.4 \%$, but most of them translated to the isomeride. Compared with the Fenton, photo-Fenton and UV light irradiation processes, we deduces that photo-Fenton can get the better degradation efficiency of 4-MBC, and, Fenton reagents and light irradiation are synergistic.
\end{abstract}

Keywords. 4-MBC, fenton reaction, light degradation, photo-fenton.

\section{Introduction}

Pharmaceutical and Personal Care Products(PPCPs) include drugs, hormones, fragrances, cosmetics, eta, which have attracted much public and scientific attention due to widespread contamination in aquatic environment. Among them, sunscreen cosmetic products have been used for more than 80 years [1], and its essential components are UV-filters. The main concern used to focus merely on their utility and efficiency as UV-filters, but, only very recently, concern has been raised regarding their path and their endocrine disrupting activity in the environment. UV-filters enter the aquatic environment either directly via wash-off from skin during swimming and bathing activities, or indirectly via wastewater from wastewater treatment plants (WWTPs) [2]. Due to the high lipophilicity and relative stability against biotic degradation, UV-filters have been shown to accumulate in the food chain by bioaccumulation and potential biomagnification [3]. Studies have proved that some organic UV-filters exhibit endocrine disrupting activity [4, 5].

4-methylbenzylidene camphor (4-MBC) is an organic camphor derivative which has the ability to protect the skin against UV-B radiation, and it is one of the most commonly employed UV-filters [6]. However, it has been shown to accumulate in the environment. The concentration of $4-\mathrm{MBC}$ can reach to $113 \pm 7 \mathrm{ng} \cdot \mathrm{L}-1$ in the surface water around Majorca Island [7]. It also can be detected in the muscle tissue of fish from seven small Swiss Rivers, all receiving inputs from wastewater treatment plants [8]. And even in tap water, 4-MBC also exist and the concentration can reach to $35 \mathrm{ng} \cdot \mathrm{L}-1$ [9]. 4-MBC has also been proved to have endocrine disrupting activity. Researches demonstrate that it can affect the rats' development of reproductive organs [10], the number of embryos of Pantipodarum [11], and accelerate the cell proliferation in MCF-7 breast cancer cells [12].

Studies reveal that UV-filters cannot be degraded completely in WWTPs, and 4-MBC is the most prevalent UV filter detected in treated wastewater[13].To prevent the environmental problems caused by 4-MBC from being more serious, finding effective method to degrade 4-MBC is essential. Fenton and photo-fenton, which are the commonly used methods in degrading organic pollutants, were employed to degrade 4-MBC in the research. orthogonal experiments were employed to verify the interaction effects of factors responsible ( $\mathrm{Fe} 2+, \mathrm{H} 2 \mathrm{O} 2, \mathrm{pH}$ and reaction time) on the degradation efficiency of 4-MBC. UV light irradiation was also explored. The degradation eciency of Fenton, photo-Fenton and UV light irradiation were compared. The degradation efficiency was determined by HPLC (High Performance Liquid Chromatography). To the best of our knowledge, this is the first time todo the work.

\section{Materials and Methods}




\subsection{Materials and Instruments}

4-MBC was purchased from Brilliance Biochemical Company (Beijing, China) and the purity was higher than $99 \%$. Acetonitrile (HPLC grade) was obtained from Damao Chemical Regent Factory (Tianjin, China).Analytically pure grade $\mathrm{H}_{2} \mathrm{O}_{2}$ (30\%), $\mathrm{FeSO}_{4} \cdot 7 \mathrm{H}_{2} \mathrm{O}, \mathrm{NaOH}$ used in the experiments were purchased from Damao Chemical Regent Factory(Tianjin,China) and $\mathrm{H}_{2} \mathrm{SO}_{4}$ was from Tieta (Laiyang, China). All reagents were used without further purification. High-purity water $(18.2 \mathrm{M} \Omega \mathrm{cm})$ was used throughout all experiments, and it was prepared on an ELGA purelab flex system (ELGA, Veolia Water, Marlow, UK).

Photochemical reactor (BL-GHX) was manufactured by Bilon Instrument Company (shanghai, China).It was mainly comprised of light source, cylindrical reactor, magnetic stirrer and circulating cooling system. Mercury lamp was employed (300W) as light source and the lamp was vertically located in the center of the reactor. Orbital shaker (HV-4) used in the experiments was manufactured by guohua, (Changzhou, China). A Leici PHS-3C pH meter (Shanghai Leici Corporation, Shanghai, China) was used for $\mathrm{pH}$ measurements. The LC system comprised a Shimadzu SPD-20A UV detector, and a LC-20AT high-pressure solvent delivery pump with a $20 \mathrm{~mL}$ sample loop injector. The column used in our experiments was Anasil AQ-C18 $(25 \mathrm{~cm} \times 4.6 \mathrm{~mm}, 5 \mu \mathrm{m})$.

\subsection{Fenton process}

In Fenton process, the vital factors are the initial concentration of the 4-MBC, the dosages of $\mathrm{H}_{2} \mathrm{O}_{2}, \mathrm{pH}$ value, amount of $\mathrm{Fe}^{2+}$, reaction time. For the aim of the research is to assess the ability of Fenton in degrading 4-MBC, we fixed the initial concentration of 4-MBC and chose factors $\left(\mathrm{Fe}^{2+}, \mathrm{H}_{2} \mathrm{O}_{2}, \mathrm{pH}\right.$ and reaction time) as variables and evaluate their effect on degradation. Orthogonal experimental design was employed to optimize the reaction conditions of Fenton process. The Fenton reaction was carried out in a conical flask $(200 \mathrm{~mL})$. The initial concentration of 4-MBC aqueous was $10 \mathrm{mg} / \mathrm{L}$ and the volume of reaction solutions was $50 \mathrm{~mL}$. The addition of $\mathrm{H}_{2} \mathrm{O}_{2}$ and $\mathrm{FeSO}_{4} \cdot 7 \mathrm{H}_{2} \mathrm{O}$ were at beginning. The $\mathrm{pH}$ value, initial concentrations of $\mathrm{H}_{2} \mathrm{O}_{2}$ and $\mathrm{FeSO}_{4} \cdot 7 \mathrm{H}_{2} \mathrm{O}$ were listed in Table 1. All the reaction solutions were well mixed and were vibrated by orbital shaker during the reaction. The whole Fenton process was working in darkness.

Table 1. Factors and levels of the Fenton's orthogonal experimental design.

\begin{tabular}{|c|c|c|c|c|}
\hline Factors & $\mathrm{A}\left(\mathrm{H}_{2} \mathrm{O}_{2}: \mathrm{Fe}^{2+*}\right)$ & $\mathrm{B}\left(\mathrm{H}_{2} \mathrm{O}_{2}\right)$ & $\mathrm{C}(\mathrm{Time})$ & $\mathrm{D}(\mathrm{pH})$ \\
\hline & $5: 1$ & $0.1 \mathrm{~mL}$ & $15 \mathrm{~min}$ & 2 \\
\hline Levels & $10: 1$ & $0.5 \mathrm{~mL}$ & $30 \mathrm{~min}$ & 3 \\
\hline & $15: 1$ & $1.0 \mathrm{~mL}$ & $45 \mathrm{~min}$ & 4 \\
\hline
\end{tabular}

* $\mathrm{H}_{2} \mathrm{O}_{2}: \mathrm{Fe}^{2+}$ is the mole ratio.

\subsection{UV light irradiation}

In UV light irradiation process, the vital factors are reaction time, light source and the initial concentration of 4-MBC. For the feature of absorbing UV light, mercury lamp was employ as the light source. Same to the Fenton process, the concentration of 4-MBC was not thought about. Just reaction time was taken as the factor. Photochemical reactor was employed in UV light irradiation processes. Degradation was performed on $200 \mathrm{~mL} 4-\mathrm{MBC}$ aqueous. During the reaction, about $3 \mathrm{~mL}$ samples were took out at $30 \mathrm{~min}, 45 \mathrm{~min}, 60 \mathrm{~min}, 75 \mathrm{~min}$ and 90 min respectively.

\subsection{Photo-Fenton Process}

The major factors affecting the photo-Fenton process are the initial concentration of the 4-MBC, the dosages of $\mathrm{H}_{2} \mathrm{O}_{2}, \mathrm{pH}$ value, amount of $\mathrm{Fe}^{2+}$, reaction time and the light source ${ }^{[14]}$. According to Fenton and irradiation processes, we employed mercury lamp as the light source, fixed the initial concentration of 4-MBC and chose factors $\left(\mathrm{Fe}^{2+}, \mathrm{H}_{2} \mathrm{O}_{2}, \mathrm{pH}\right.$ and reaction time) as variables and evaluate their effect on degradation. Orthogonal experimental design was also employed to optimize the reaction conditions of photo-Fenton process. The factors and levels of the orthogonal experimental design were listed in Table 2. The addition of $\mathrm{H}_{2} \mathrm{O}_{2}$ and $\mathrm{FeSO}_{4} \cdot 7 \mathrm{H}_{2} \mathrm{O}$ were at beginning. The whole photo-Fenton process was carried out in the photochemical reactor. The initial concentration of $4-\mathrm{MBC}$ aqueous was $10 \mathrm{mg} / \mathrm{L}$. Degradation of each group was performed on $200 \mathrm{~mL} 4-\mathrm{MBC}$ aqueous. 
Table 2. Factors and levels of the photo- Fenton's orthogonal experimental design.

\begin{tabular}{|c|c|c|c|c|}
\hline Factors & $\mathrm{A}\left(\mathrm{H}_{2} \mathrm{O}_{2}: \mathrm{Fe}^{2+*}\right)$ & $\mathrm{B}\left(\mathrm{H}_{2} \mathrm{O}_{2}\right)$ & $\mathrm{C}($ Time $)$ & $\mathrm{D}(\mathrm{pH})$ \\
\hline & $5: 1$ & $0.1 \mathrm{~mL}$ & $30 \mathrm{~min}$ & 3 \\
\hline Levels & $10: 1$ & $0.5 \mathrm{~mL}$ & $45 \mathrm{~min}$ & 5 \\
\hline & $15: 1$ & $1.0 \mathrm{~mL}$ & $60 \mathrm{~min}$ & 7 \\
\hline
\end{tabular}

$* \mathrm{H}_{2} \mathrm{O}_{2}: \mathrm{Fe}^{2+}$ is the mole ratio.

\subsection{Analytical procedures}

The concentration of 4-MBC in solution was detected by HPLC (High Performance Liquid Chromatography). Before being injected into the LC system, the solution samples were passed through $0.45 \mu \mathrm{m}$ Nylon, polyamide membranes filters. The column used in our experiments was Anasil AQ-C18 $(25 \mathrm{~cm} \times 4.6 \mathrm{~mm}$ I.D. $5 \mu \mathrm{m}$ packing). The column temperature was maintained at $30^{\circ} \mathrm{C}$. Water/acetonitrile $(20 / 80 \%, v / v)$ was used for the isocratic elution of the analyte. Spectrum identification was performed at the wavelength of $300 \mathrm{~nm}$ [15].

\section{Results}

\subsection{Fenton process}

From Table 3 , it could be saw that the highest degradation reached to $66.01 \%$. It could be deduced from the range value (R) in table 3: RB $>\mathrm{RA}>\mathrm{RD}>\mathrm{RC}$. It meant that the dosage of $\mathrm{H}_{2} \mathrm{O}_{2}$ had the greatest effect on the degradation of 4-MBC in Fenton process, then followed by the portion of $\mathrm{H}_{2} \mathrm{O}_{2}$ and $\mathrm{Fe}^{2+}$, but the reaction time had the less effect. And the $\mathrm{K}$ value revealed that when the portion of $\mathrm{H}_{2} \mathrm{O}_{2}$ and $\mathrm{Fe}^{2+}$ was 1:5, the dosage of $\mathrm{H}_{2} \mathrm{O}_{2}$ was $1 \mathrm{~mL}$, the reaction time was 30 min and the $\mathrm{pH}$ value was 3 , the highest degradation could be reached. Fig. 1 illustrated the trend curves of different level vs different factor.

\subsection{Irradiation process}

When mercury lamp was used alone to degrading the 4-MBC, the degradation of 4-MBC at different time was tested (Fig.2). It revealed that as time growing, the concentration of 4-MBC was decreasing. After irradiating 90 min, the concentration decreased $85.4 \%$.

Table 3. Orthogonal experimental design and results for Fenton reactions, $\mathrm{C}_{0}(4-\mathrm{MBC})=10 \mathrm{mg} / \mathrm{L}$.

\begin{tabular}{|c|c|c|c|c|c|}
\hline \multirow[t]{2}{*}{ No. } & \multicolumn{4}{|c|}{ Factors } & \multirow{2}{*}{$\begin{array}{c}\text { Degradation } \\
\text { (\%) }\end{array}$} \\
\hline & $\mathbf{A}$ & B & C & D & \\
\hline 1 & $1 / 5$ & 0.1 & 15 & 2 & 32.14 \\
\hline 2 & $1 / 5$ & 0.5 & 30 & 3 & 65.25 \\
\hline 3 & $1 / 5$ & 1.0 & 45 & 4 & 64.51 \\
\hline 4 & $1 / 10$ & 0.1 & 30 & 4 & 34.70 \\
\hline 5 & $1 / 10$ & 0.5 & 45 & 2 & 40.52 \\
\hline 6 & $1 / 10$ & 1.0 & 15 & 3 & 66.01 \\
\hline 7 & $1 / 15$ & 0.1 & 45 & 3 & 18.01 \\
\hline
\end{tabular}




\begin{tabular}{|c|c|c|c|c|c|}
\hline 8 & $1 / 15$ & 0.5 & 15 & 4 & 29.37 \\
\hline 9 & $1 / 15$ & 1.0 & 30 & 2 & 46.04 \\
\hline $\mathrm{K} 1$ & 161.9 & 84.85 & 127.52 & 118.7 & \\
\hline $\mathrm{K} 2$ & 141.23 & 135.14 & 145.99 & 149.27 & \\
\hline $\mathrm{K} 3$ & 93.42 & 176.56 & 123.04 & 127.95 & \\
\hline $\mathrm{R}$ & 68.48 & 91.97 & 22.95 & 30.57 & \\
\hline
\end{tabular}

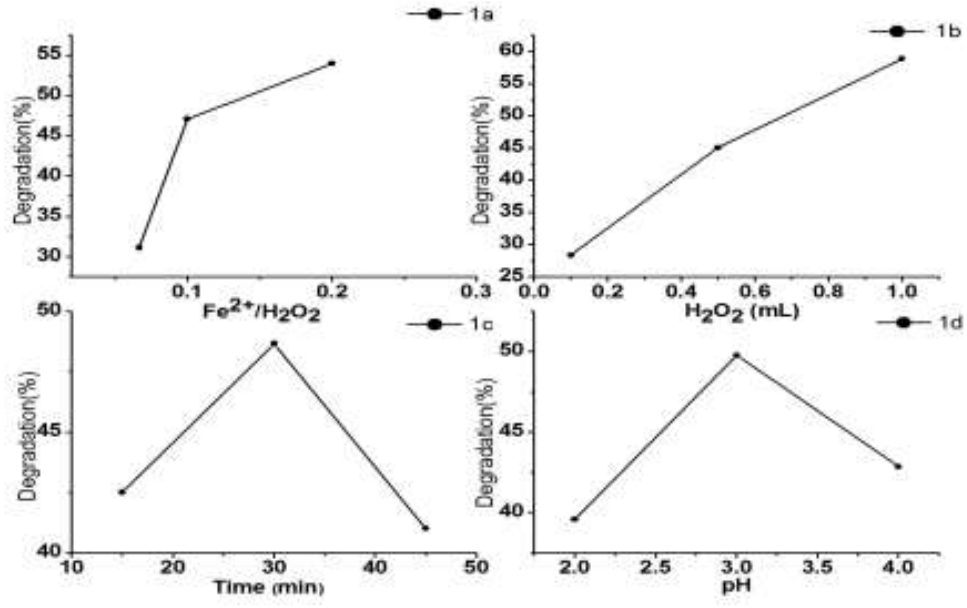

Fig.1. Trend curves of different level vs different factor of Fenton processes.

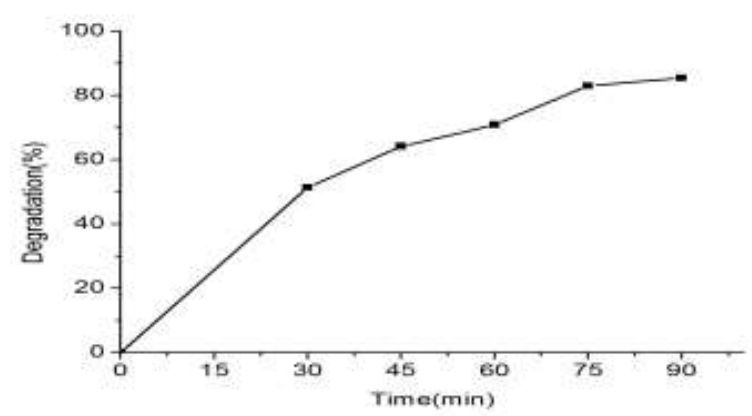

Fig.2. The effect of irradiation time on the degradation of 4-MBC. $\mathrm{pH}=7, \mathrm{C}_{0}(4-\mathrm{MB})=10 \mathrm{mg} / \mathrm{L}$.

\subsection{Photo-Fenton process}

The reaction condition and the degradation of each group were listed in Table 4. It could be deduced from the range value $\mathrm{R}$ in table 4: $\mathrm{RB}>\mathrm{RC}>\mathrm{RD}>\mathrm{RA}$. It meant that the dosage of $\mathrm{H}_{2} \mathrm{O}_{2}$ had the greatest effect on the degradation of 4-MBC in photo-Fenton process, then followed by the reaction time, but the portion of $\mathrm{H}_{2} \mathrm{O}_{2}$ and $\mathrm{Fe}^{2+}$ had the less effect. The degradation of 4-MBC varied between $76.77 \%$ and $96.71 \%$. The $\mathrm{K}$ value revealed that when the portion of $\mathrm{H}_{2} \mathrm{O}_{2}$ and $\mathrm{Fe}^{2+}$ was 5: 1, the dosage of $\mathrm{H}_{2} \mathrm{O}_{2}$ was $0.1 \mathrm{~mL}$, the reaction time was $60 \mathrm{~min}$ and the $\mathrm{pH}$ value was 3 , the highest degradation could be reached. 
Table 4. Orthogonal experimental design and results for photo-Fenton reactions, $\mathrm{C}_{0}(4-\mathrm{MBC})=10 \mathrm{mg} / \mathrm{L}$.

\begin{tabular}{|c|c|c|c|c|c|}
\hline \multirow[t]{2}{*}{ No. } & \multicolumn{4}{|c|}{ Factors } & \multirow{2}{*}{$\begin{array}{c}\text { Degradation } \\
(\%)\end{array}$} \\
\hline & A & B & $\mathrm{C}$ & D & \\
\hline 1 & $1 / 5$ & 0.1 & 30 & 3 & 95.99 \\
\hline 2 & $1 / 5$ & 0.5 & 45 & 5 & 86.89 \\
\hline 3 & $1 / 5$ & 1.0 & 60 & 7 & 88.21 \\
\hline 4 & $1 / 10$ & 0.1 & 45 & 7 & 86.08 \\
\hline 5 & $1 / 10$ & 0.5 & 60 & 3 & 96.71 \\
\hline 6 & $1 / 10$ & 1.0 & 30 & 5 & 76.77 \\
\hline 7 & $1 / 15$ & 0.1 & 60 & 5 & 96.29 \\
\hline 8 & $1 / 15$ & 0.5 & 30 & 7 & 83.73 \\
\hline 9 & $1 / 15$ & 1.0 & 45 & 3 & 87.60 \\
\hline K1 & 271.09 & 278.36 & 256.49 & 280.3 & \\
\hline K2 & 259.56 & 267.33 & 260.57 & 259.95 & \\
\hline K3 & 267.62 & 252.58 & 281.21 & 258.02 & \\
\hline $\mathrm{R}$ & 11.53 & 25.78 & 24.72 & 22.28 & \\
\hline
\end{tabular}

\section{Discussion}

Figure $1 \mathrm{a}$ and Figure $1 \mathrm{~b}$ revealed that in Fenton process, along with the increase of the dosage of $\mathrm{FeSO} 4 \cdot 7 \mathrm{H} 2 \mathrm{O}$ and $\mathrm{H} 2 \mathrm{O} 2$, the degradation was increase. More $\mathrm{FeSO} 4 \cdot 7 \mathrm{H} 2 \mathrm{O}$ and $\mathrm{H} 2 \mathrm{O} 2$ were not employed, for the dilution effect caused by $\mathrm{H} 2 \mathrm{O} 2$ and the economy issue. The degradation of $4-\mathrm{MBC}$ varied between $18.01 \%$ and $66.01 \%$ in Fenton process. Even the highest degradation was lower than the photo-Fenton process's lowest degradation. It was known that the Fenton and photo-Fenton reactions are mostly based on the production of hydroxyl radical $\mathrm{HO} \cdot$ in water. As it is classically described, hydroxyl radicals are produced in this technique by the decomposition of hydrogen peroxide when reacting with ferrous ions (reaction 1) [16]. Irradiation with sunlight, an artificial light source of wavelength $180-400 \mathrm{~nm}$, or even in the visible spectra [17] increases the rate of contaminant degradation mainly by stimulating the $\mathrm{Fe} 3+$ to $\mathrm{Fe} 2+$ reduction (reaction 2) [16]. Thus, the degradation of 4-MBC in photo-Fenton reaction is higher than Fenton reaction.

$\mathrm{H}_{2} \mathrm{O}_{2}+\mathrm{Fe}^{2+} \rightarrow \mathrm{Fe}^{3+}+\mathrm{HO}^{-}+\mathrm{HO}$.

$\mathrm{Fe}^{3+}+\mathrm{H}_{2} \mathrm{O}+h v \rightarrow \mathrm{Fe}^{2+}+\mathrm{H}^{+}+\mathrm{HO}$.

It was known that 4-MBC could exist as a (Z) or (E)-isomer due to the exocyclic carbon-carbon (styrene) double bond, and 4-MBC was shown to consist entirely of $(\mathrm{E})$ - in commercial sunscreen products ${ }^{[18]}$. But when exposure to light, (E)-isomer is isomerized reversibly to $(\mathrm{Z})$-isomer ${ }^{[19]}$. Thus, although the degradation could reach to $85.41 \%$ after irradiating $90 \mathrm{~min}$, we thought the light promoted the 4-MBC to translate to its isomeride, but did not decompose it. 


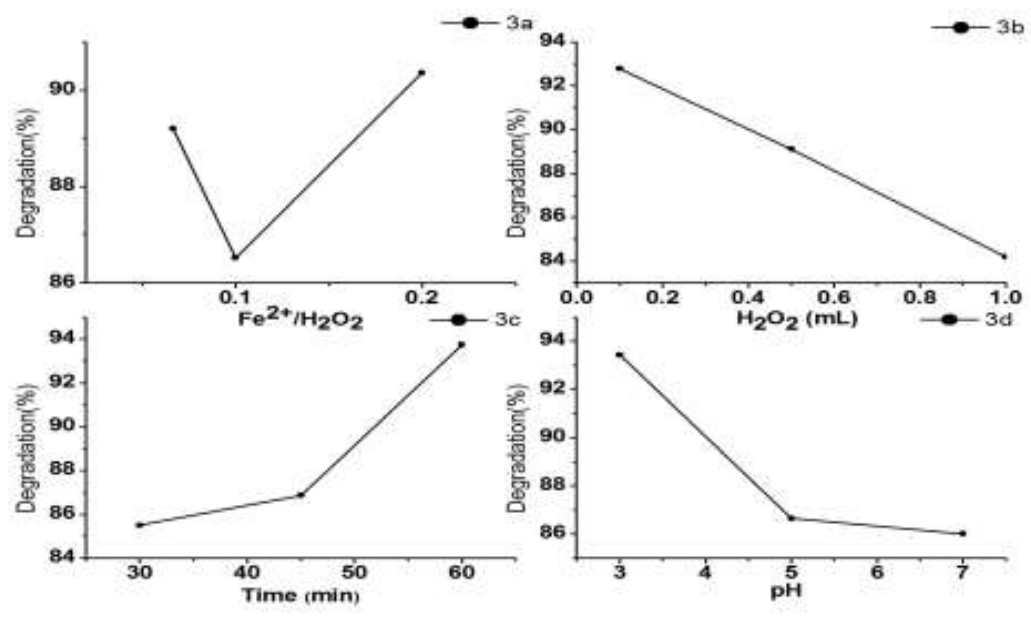

Fig.3. Trend curves of different level vs different factor of photo-Fenton processes.

Figure 3 illustrated the trend curves of different level vs different factors in photo-Fenton process. And Fig.3a revealed that the degradation rate of 4-MBC decreased firstly, and then increased. Comparing to Fig. 1a, we speculated that the ferric ion weakened the irradiancy. The efficiency of Fenton reaction on degradation was better than the effect of irradiation when the concentration of ferric ion was high. Then the degradation decreased, because along with the decrease of the ferric ion, the efficiency of the Fenton reaction was also decreased and the irradiation process could not work well for the weakening of the irradiation by ferric ion. With the continuous decrease of the ferric iron, the degradation increased. We thought that irradiation make a significant contribution to the degradation in this stage. Fig. $3 \mathrm{~b}$ revealed that along with the increase of the $\mathrm{H} 2 \mathrm{O} 2$, the degradation was decreased. It was because that the $\mathrm{H} 2 \mathrm{O} 2$ also could consume the hydrogen radicals, which was achieved by reaction (3) [20]. Thus the degradation of 4-MBC would decrease when the amount of $\mathrm{H} 2 \mathrm{O} 2$ increase. Fig. $3 \mathrm{c}$ indicated that the degradation increased with the time going and Figure $3 \mathrm{~d}$ indicated that the degradation decreased with the $\mathrm{pH}$ value increasing.

$\cdot \mathrm{OH}+\mathrm{H}_{2} \mathrm{O}_{2} \rightarrow \cdot \mathrm{O}_{2}^{-}+\mathrm{H}_{2} \mathrm{O}$

\section{Conclusion}

When the initial concentration of 4-MBC was $10 \mathrm{mg} / \mathrm{L}$, and the dosage of the Fenton regents $\left(\mathrm{Fe}^{2+}, \mathrm{H}_{2} \mathrm{O}_{2}\right)$ were at the same level, degradation efficiency of 4-MBC in photo-Fenton process was better than Fenton process and the best degradation reached to $96.71 \%$ and $66.01 \%$ respectively. In UV light irradiation process, the concentration of 4-MBC decreased $85.4 \%$. But most of them translated to the isomeride. Compared with the Fenton and photo-Fenton process, we deduced that Fenton reagents and light irradiation were synergistic.

\section{Conflict of interest}

The author confirms that this article content has no conflict of interest.

\section{References}

1. D.L. Giokas, A. Salvador, and A. Chisvert: UV filters: from sunscreens to human body and the environment. Trends in Analytical Chemistry. vol. 26(2007), p. 360-374.

2. F. Karl, Z. Armin, and R. Maja: Widespread occurrence of estrogenic UV-filters in aquatic ecosystems in Switzerland. Environmental Pollution. vol. 158(2010), p. 1817-1824.

3. M. S. Díaz-Cruz, and D. Barceló: Chemical analysis and ecotoxicological effects of organic UV-absorbing compounds in aquatic ecosystems. Trends in Analytical Chemistry. vol.28(2009), p. 708-717. 
4. S. Durrer, K. Maerkel, M. Schlumpf, and W. Lichtensteiger: Estrogen target gene regulation and coactivator expression in rat uterus after developmental exposure to the ultraviolet filter 4-methylbenzylidene camphor. Endocrinology. vol. 146(2005), p. 2130-2139.

5. M. Schlumpf, S. Durrer, O. Faass, C. Ehnes, M. Fuetsch, C. Gaille, M. Henseler, L. Hofkamp, K. Maerkel, S. Reolon, B. Timms, J. A. F. Tresguerres, and W. Lichtensteiger: Developmental toxicity of UV filters and environmental exposure: a review. International Journal of Andrology. vol.31(2008), p. 144-151.

6. M. Badia-Fabregat, C. E. Rodríguez-Rodríguez, P. Gago- Ferrero, A. Olivares, B. Piña, M. S. Díaz-Cruz, T. Vicent, D. Barceló, and G. Caminal: Degradation of UV-filters in sewage sludge and 4-MBC in liquid medium by the ligninolytic fungus trametes versicolor. Journal of Environmental Management. vol. 104(2012), p. 114-120.

7. A.Tovar-Sánchez, D. Sánchez-Quiles, G.Basterretxea, J. L. Benedé, A. Chisvert, A. Salvador, I. Moreno-Garrido, and J. Blasco: Sunscreen products as emerging pollutants to coastal waters. PLOS ONE. vol. 8(2013), p. 1-8.

8. HR. Buser, M. E. Balmer, P. Schmid, and M. Kohler: Occurrence of UV-filters 4-methylbenzylidene camphor and octocrylene in fish from various Swiss rivers with inputs from wastewater treatment plants. Environmental Science \& Technology. vol. 40(2006), p. 1427-1431.

9. M. S. Díaz-Cruz, P. Gago-Ferrero, M. Llorca, and D. Barceló: Analysis of UV filters in tap water and other clean waters in Spain. Analytical and Bioanalytical Chemistry. vol. 402(2012), p. 2325-2333.

10. M. Schlumpf, B. Cotton, M.Conscience, V. Haller, B. Steinmann, and W. Lichtensteiger: In vitro and in vivo estrogencity of UV screens. Environmental Health Perspectives. vol. 109(2001), p. 239-244.

11. C. SchmittM. Oetken, O. Dittberner, M. Wagner, and J. Oehlmann: Endocrine modulation and toxic effects of two commonly used UV screens on the aquatic invertebrates Potamopyrgus antipodarum and Lumbriculus variegates. Environmental Pollution. vol. 152(2008), p. 322-329.

12. A. Klann, G. Levy, I. Lutz, C. Müller, Werner Kloas, and JP. Hildebrandt: Estrogen-like effects of ultraviolet screen 3-(4-methylbenzylidene)-camphor (Eusolex 6300) on cell proliferation and gene induction in mammalian and amphibian cell. Environmental Research. vol.97(2005), p. 274-281.

13. M. E. Balmer, HR. Buser, M. D. Müller, and T. Poiger,’Occurrence of some organic UV-filters in wastewater, in surface waters, and in fish from Swiss lakes. Environmental Science \& Technology. vol. 39(2005), p. 953-962.

14. A.S. Stasinakis: Use of selected advanced oxidation processes (AOPs) for wastewater tratement - a mini review. Global Nest. vol. 10(2008), p. 376-385.

15. V.A. Sakkas, P. Calza, M. Azharul Islam, C. Medana, C. Baiocchi, K. Panagiotou, and T. Albanis: TiO2/H2O2 mediated photocatalytic transformation of UV filter 4-methylbenzylidene camphor (4-MBC) in aqueous phase: statistical optimization and photoproduct analysis. Applied Catalysis B: Environmental, vol. 90(2009), p. 526-534.

16. C. Walling: Fenton's reagent revisited. Accounts of Chemical Research. vol. 8(1974), p. 125-131.

17. E. Oliveros, O. Legrini, M. Hohl, T. Müller, and A. M. Braun: Industrial waste water treatment: large scale development of a light enhanced Fenton reaction. Chemical Engineering and Processing. vol. 36(1997), p. $397-405$.

18. HR. Buser, M.D. Müller, M. E. Balmer, T. Poiger, and I. J. Buerge: Stereoisomer composition of the chiral UV filter 4-methylbenzylidene camphor in environmental samples. Environmental Science \& Technology. vol. 39(2005), p. 3013-3019.

19. R. Rodil, M. Moeder, R. Altenburger, and M. Schmitt-Jansen: Photostability and phytotoxicity of selected sunscreen agents and their degradation mixtures in water. Analytical and Bioanalytical Chemistry. vol. 395(2009), p. 1513-1524.

20. N. H. Ince, D. T. Gönenç: Treatability of a textile azo dye by UV/H2O2. Environmental Technology. vol. 18(1996), p. $179-185$. 